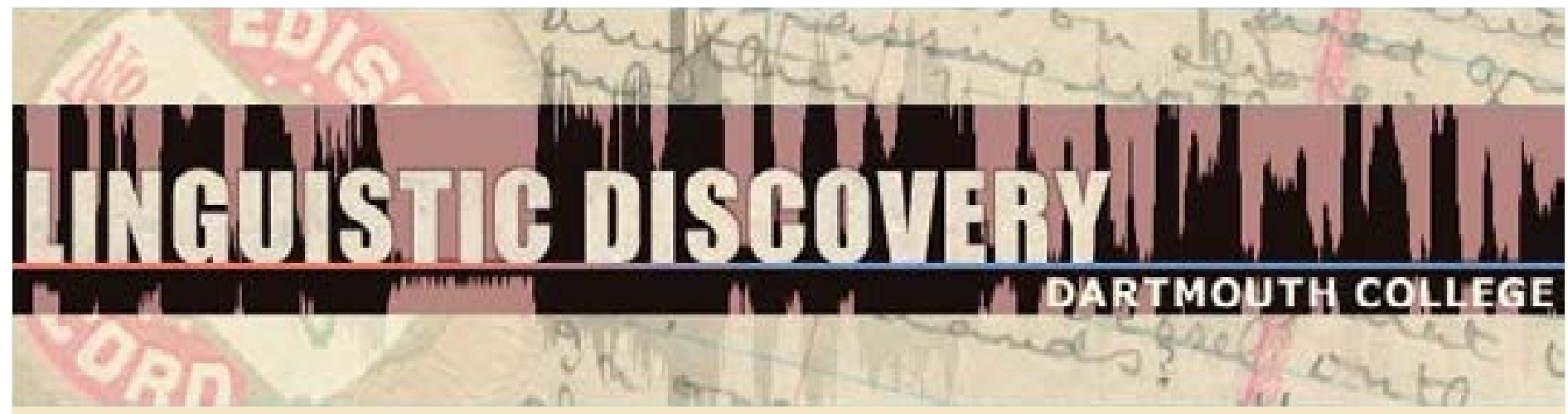

Volume 8 Issue 1 2010

\section{An Implicational Map of Parts of Speech}

Kees Hengeveld \& Eva van Lier

University of Amsterdam \& Lancaster University

doi: $10.1349 / P S 1.1537-0852 . A .348$

url: http://journals.dartmouth.edu/cgi-bin/WebObjects/ Journals.woa/1/xmlpage/1/article/348
Linguistic Discovery

Published by the Dartmouth College Library Copyright to this article is held by the authors. ISSN 1537-0852 linguistic-discovery.dartmouth.edu 


\title{
An Implicational Map of Parts of Speech
}

\author{
Kees Hengeveld \& Eva van Lier
}

University of Amsterdam \& Lancaster University

In this paper we present a two-dimensional implicational map of parts of speech. We show that this map constitutes an improvement with respect to the one-dimensional parts of speech hierarchy originally proposed in Hengeveld (1992) in terms of typological adequacy. In addition, our map is an innovation in relation to traditional semantic maps since it is implicational in nature and since the typological implications it contains are hierarchically ordered with respect to one another. Finally, our proposal shows that the analytical primitives underlying map models need not be exclusively semantic in nature, but may also include other dimensions, in this case pragmatic ones.

\section{Introduction ${ }^{1}$}

The aim of this paper is twofold. First, we argue that the one-dimensional parts of speech hierarchy originally proposed in Hengeveld (1992) should be reanalyzed as the superficial manifestation of a two-dimensional implicational map. We show that this new map is more adequate than the earlier parts of speech hierarchy since the new map covers a number of counterexamples to the earlier hierarchy, without loss of accuracy.

Second, we explore the status of our proposal in relation to semantic map modelling in general terms. The map that we propose here shows that analytical primitives need not be exclusively semantic in nature but may also include pragmatic dimensions just as they might contain morphosyntactic or phonological ones. In addition, our model shows that implicational maps, which embody a series of implicational universals (Haspelmath 1997; 2003), can consist of several different types of implications that are hierarchically ordered with respect to one another.

This paper starts out with a brief description in Section 2 of the original parts of speech hierarchy. It then proceeds to present three types of counterexamples to this version of the hierarchy in Section 3. Section 4 presents the new two-dimensional map of parts of speech, and the typological adequacy of the new map is discussed in Section 5. Finally, in Section 6 we conclude with a discussion of the nature of implicational maps in general terms.

\section{The Former Parts of Speech Hierarchy}

Hengeveld, Rijkhoff, and Siewierska (2004), based on Hengeveld (1992), classifies basic and derived lexemes in terms of their distribution across four propositional functions (a term introduced by Croft 2000, 2001), which are tabulated in Figure 1.

\begin{tabular}{|l|c|c|}
\cline { 2 - 3 } \multicolumn{1}{c|}{} & head & modifier \\
\hline predicate phrase & 1 & 4 \\
\hline referential phrase & 2 & 3 \\
\hline
\end{tabular}

Figure 1: Lexemes and propositional functions

\footnotetext{
${ }^{1}$ We are indebted to Michael Cysouw and an anonymous reviewer for comments on an earlier version of this paper.
} 
Figure 1 shows that the functional positions 1-4 are based on two parameters, one involving the opposition between predication and reference, the other between heads and modifiers. Together, these two parameters define the following four propositional functions: head and modifier of a predicate phrase, and head and modifier of a referential phrase. The four propositional functions and their lexical expression can be illustrated by means of the English sentence in (1).

\section{(1) The tall $_{A}$ girl $_{N}$ sings $_{V}$ beautifully ${ }_{M A d v}$}

English can be said to display separate lexeme classes of verbs, nouns, adjectives, and (derived) manner adverbs, on the basis of the distribution of these classes across the four propositional functions identified in Figure 1: Verbs like 'sing' are used as heads of predicate phrases; nouns like 'girl' as heads of referential phrases; adjectives like 'tall' as modifiers in referential phrases; and (derived) manner adverbs like 'beautifully' as modifiers in predicate phrases. Crucially, none of the content lexemes in (1) could be used directly in another propositional function, i.e. without morphosyntactic adaptation. Thus, in this example there is a one-to-one relation between propositional function and lexeme class. Parts of speech systems of this type are called differentiated, and the lexical classes can all be said to be specialized for a certain propositional function.

There are other parts of speech systems in which there is no one-to-one relation between the four propositional functions identified and the lexeme classes available. These systems are of two types. In the first type, a single class of lexemes is used in more than one propositional function. Such lexeme classes, and the parts of speech systems in which they appear, are called flexible. The second type is called rigid. Rigid systems resemble differentiated systems to the extent that both consist only of lexemes classes that are specialized, i.e. dedicated to the expression of a single function. However, rigid systems are characterized by the fact that they do not have four lexeme classes - one for each of the four propositional functions. Rather, for one or more functions a lexeme class is lacking. The following examples illustrate the difference between these flexible and rigid parts of speech systems. In Turkish (Göksel \& Kerslake 2005:49) the same lexical item may be used indiscriminately as the head of a referential phrase (2), as a modifier within a referential phrase (3), and as a modifier within a predicate phrase (4):

(2) güzel-im

beauty-1POSS

'my beauty'

(3) güzel bir kopek

beauty ART dog

'a beautiful dog'

(4) Güzel konuştu.

beauty s/he.spoke

'S/he spoke well.'

The situation in Krongo is rather different. This language has basic classes of nouns and verbs, but not of adjectives and manner adverbs. In order to modify a head noun within a referential 
phrase, a relative clause has to be formed on the basis of a verbal lexeme, as illustrated in (5) and

(6) (Reh 1985:251):

(5) Álímì bìiti.

M.IPFV.be.cold water.

'The water is cold.'

(6) bìiti $\eta$-álímì

water CONN-M.IPFV.be.cold

'cold water' (lit. 'water that is cold')

In (6) the inflected verb form álimi 'is cold' is used within a relative clause introduced by the bound connective $\eta$-. This is the general relativizing strategy in Krongo, as illustrated by the following examples (Reh 1985:256):

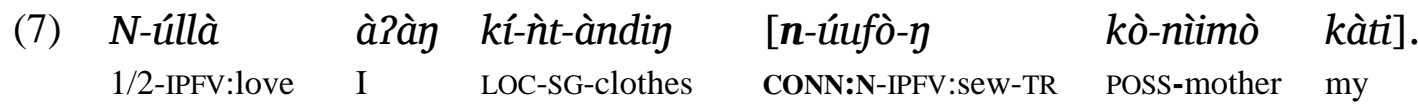

'I love the dress that my mother is sewing.'

(8) káaw [m-àasàlàa-tí àakù $]$

person CONN:F-PFV:look.at-1SG she

'the woman that I looked at (her)'

This shows that álimì in (6) is not a lexically derived adjective but a verb that serves as the main predicate of a relative clause. Since this is the only attributive strategy available in Krongo, we can say that the propositional function of modification is expressed by relative clauses in this language, not by lexical modifiers.

The same strategy is used to modify a verbal head within a predicate phrase, as illustrated in (9) (Reh 1985:345):

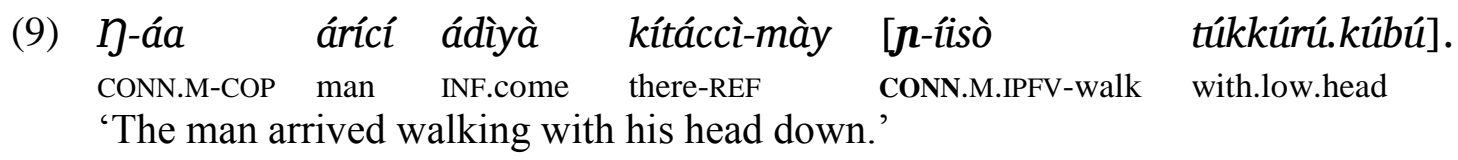

The bound subordinating connector morpheme is added to the verb form ísò 'walk' in (9). This verb again fulfils the propositional function of head of a predicate phrase within the adverbial subordinate clauses, which as a whole fulfils the function of modifier in a (main) predicate phrase.

In sum, the difference between English (differentiated), Turkish (flexible), and Krongo (rigid), is that (i) Turkish has a class of flexible lexical items that may be used in several propositional functions, where English uses three specialized classes (nouns, adjectives, and manner adverbs), and that (ii) Krongo lacks classes of lexical items for the modifier functions, where English does have lexical classes of adjectives and manner adverbs. Krongo must resort to alternative syntactic strategies to compensate for the absence of a lexical solution. These differences may be represented as in Figure 2. 


\begin{tabular}{|l|l|l|l|l|}
\hline language & $\begin{array}{l}\text { head of } \\
\text { pred. phrase }\end{array}$ & $\begin{array}{l}\text { head of } \\
\text { ref. phrase }\end{array}$ & $\begin{array}{l}\text { modifier of } \\
\text { ref.phrase }\end{array}$ & $\begin{array}{l}\text { modifier of } \\
\text { pred. phrase }\end{array}$ \\
\hline Turkish & verb & non-verb & \multicolumn{3}{|l|}{} \\
\hline English & verb & noun & adjective & manner adverb \\
\hline Krongo & verb & noun & - & - \\
\hline
\end{tabular}

Figure 2: Flexible, differentiated, and rigid languages

As Figure 2 shows, Turkish and Krongo are similar in that they have two main classes of lexemes. They are radically different, however, in the extent to which one of these classes may be used in the construction of propositions: the Turkish class of non-verbs may be used in three propositional functions, while the Krongo class of nouns may be used as the head of a referential phrase only. Note that for a lexeme class to classify as flexible, the flexibility should not be a property of a subset of items but a general feature of the entire class.

Hengeveld et al. (2004) argue that the arrangement of the propositional functions in Figure 2 is not a coincidence. It is claimed to reflect the parts of speech hierarchy in (10):

$\begin{aligned} & \text { Head of } \\ & \text { Pred. phrase }\end{aligned}>\begin{aligned} & \text { Head of } \\ & \text { Ref. phrase }\end{aligned}>\begin{aligned} & \text { Modifier of } \\ & \text { Ref. phrase }\end{aligned}>\begin{aligned} & \text { Modifier of } \\ & \text { Pred. phrase }\end{aligned}$

The more to the left a propositional function is on this hierarchy, the more likely it is that a language has a specialized class of lexemes to express that function and the more to the right, the less likely. The hierarchy is implicational, so that, for example, if a language has a specialized class of lexemes to fulfil the function of modifier in referential phrase, i.e. adjectives, then it will also have specialized classes of lexemes for the functions of head of a referential phrase, i.e. nouns, and head of a predicate phrase, i.e. verbs. In addition, if a language has a flexible lexeme class that can be used to express the functions of head of a referential phrase and modifier in a predicate phrase, then it is predicted that this class can also be used for the expression of the function lying in between these two on the hierarchy, namely modifier in a referential phrase. Similarly, if a language has no lexeme class for the function of modifier in a referential phrase (i.e. no adjectives), it will also not have a lexeme class for the function of modifier in a predicate phrase (i.e. manner adverbs). Note that the hierarchy makes no claims about adverbs other than those of manner.

The hierarchy in (10), combined with the distinction between flexible, differentiated, and rigid languages, predicts a set of seven possible parts of speech systems, which is represented in Figure $3 .^{2}$ As this figure shows, it is predicted that languages can display three different degrees of flexibility (systems 1-3), three different degrees of rigidity (systems 5-7), or can be differentiated (type 4). Of the languages discussed earlier Turkish would be a type 2 language, English a type 4 language, and Krongo a type 6 language. Note that we use the term "contentive"

\footnotetext{
${ }^{2}$ In addition to the seven types listed in Figure 3, Hengeveld et al. (2004) distinguish so-called intermediate systems, showing characteristics of two systems that are contiguous in Figure 3. Consider once more Turkish. We have shown above that this language has verbs and non-verbs as lexeme classes in its basic lexeme inventory, i.e. a type 2 feature. However, Turkish also displays a productive derivational process that produces flexible modifiers, which is a type 3 feature. Taking this derived class into account, Turkish must therefore be classified as a language of type 2/3. Mandarin Chinese has open classes of verbs and nouns, a type 6 feature, but also a restricted class of adjectives (see Paul 2005), a type 5 feature. Therefore, it is classified as a language of type 5/6. Including these intermediate types, the parts of speech hierarchy predicts 13 possible types of parts of speech system.
} 
for lexical elements that may appear in any of the four functions distinguished. The term "modifier" is used for lexemes that may be used as modifiers in both predicative and referential phrases.

\begin{tabular}{|l|l|l|l|l|}
\hline $\begin{array}{l}\text { PoS } \\
\text { system }\end{array}$ & $\begin{array}{l}\text { head of pred. } \\
\text { phrase }\end{array}$ & $\begin{array}{l}\text { head of ref. } \\
\text { phrase }\end{array}$ & $\begin{array}{l}\text { modifier of ref. } \\
\text { phrase }\end{array}$ & $\begin{array}{l}\text { modifier of pred. } \\
\text { phrase }\end{array}$ \\
\hline 1 & Contentive & \multicolumn{4}{|l|}{} \\
\hline 2 & Verb & non-verb & & \\
\hline 3 & Verb & noun & Modifier & \\
\hline 4 & Verb & noun & adjective & manner adverb \\
\hline 5 & Verb & noun & adjective & \\
\hline 6 & Verb & noun & & \\
\hline 7 & Verb & & & \\
\hline
\end{tabular}

Figure 3: Parts of speech systems

For further details on and argumentation for this approach to parts of speech systems see Hengeveld et al. (2004).

\section{Counterexamples to the Former Parts of Speech Hierarchy}

In recent research (Hengeveld \& Van Lier 2008, Van Lier 2009), we have attested a number of parts of speech systems with lexeme classes that are excluded by the parts of speech hierarchy in its original form. These lexeme classes are of three types, which we will discuss here.

The first unpredicted lexeme class is a flexible class that we call nominals. ${ }^{3}$ The members of such a class can be used as the head and the modifier of a referential phrase. Nominals are attested, for instance, in Hungarian (Moravcsik 2000). This is illustrated in examples (11) and (12). In addition, these uses can be distinguished from appositional uses, which are also open to both object-denoting and property-denoting lexemes, as is illustrated in (13).
a. $A$
ház-ak-at látom.
The house-PL-ACC I.see
'I see the houses.'
b. A nagy-ok-at látom.
The big-PL-ACC I.see
'I see the big ones.'

\footnotetext{
${ }^{3}$ This counterexample is also mentioned in the Universals Archive (http://typo.uni-konstanz.de/archive/intro/), where it is illustrated with examples from Kambera.
} 

a. Ezr
$a$ bestia nö-t
utálom.
this.ACC the beast woman-ACC I.hate

'I hate this beast of a woman.'

$\begin{array}{llll}\text { b. } A & \text { kél ház-ak-at látom. } \\ \text { the } & \text { blue house-PL-ACC } & \text { I.see }\end{array}$

'I see the blue houses.'
a. A Ház-at, a szülöhely-em-et, látom.
the house-ACC the birth.place-SG.1-ACC I.see
'I see the house, my birthplace.

b. A Ház-at, a kék-et, látom.

the house-ACC the blue-ACC I.see

'I see the house, the blue one.'

The parts of speech hierarchy in (10) predicts that if a language uses the same class of lexemes in the head and modifier function within referential phrases, it will use this class for modification in predicate phrases as well. However, this turns out not to be the case in Hungarian, where the latter function is expressed by simple manner adverbs, as shown in (14), or by means of derived or case-marked nominals, as shown in (15a-b) (Kenesei et al. 1998:221, 222):

$$
\begin{aligned}
& \text { Ök mindig külön utaz-nak. } \\
& \text { They always separately travel-INDF.3SG } \\
& \text { 'They always travel separately.' }
\end{aligned}
$$
a. a hanyag-ul dolgoz-ó ember the careless-ESS work-PTC person 'the person working carelessly'
b. Attila csend-ben ki-men-t a szibá-ból. Attila silence-INESS out-go-PST.INDF.3SG the room-ELAT
'Attila left the room quietly.'

We thus have an unpredicted parts of speech class of nominals, occurring in a parts of speech system that is not compatible with Figure 3 and which should be represented as in Figure 4.

\begin{tabular}{|l|l|l|l|l|}
\hline language & $\begin{array}{l}\text { head of pred. } \\
\text { phrase }\end{array}$ & $\begin{array}{l}\text { head of ref. } \\
\text { phrase }\end{array}$ & $\begin{array}{l}\text { modifier of } \\
\text { ref. phrase }\end{array}$ & $\begin{array}{l}\text { modifier of pred. } \\
\text { phrase }\end{array}$ \\
\hline Hungarian & Verb & \multicolumn{2}{|c|}{ nominal } & manner adverb \\
\hline
\end{tabular}

Figure 4: Nominals in the PoS system of Hungarian

The second type of counterexample is a lexeme class that we will call predicatives. It is again a flexible class, more specifically one whose members can be used as both the head and the 
modifier of a predicate phrase. Predicatives are attested in Kayardild (Evans 1995:306), ${ }^{4}$ as illustrated in (16) and (17):

Ngada mirrayala-tha wangalk-I.
1SG.NOM make-ACT
'I made a boomerang.'

\section{Ngada mirrayala-tha marri-ja kangk-i. 1SG.NOM do.well-ACT hear-ACT language-LOC}

'I can understand the language well.'

Note that the lexeme which gets an adverbial interpretation cannot be analyzed as the predicate of what would be an adverbial clause since it must agree in its inflection with the main predicate. Thus Kayardild need not resort to a syntactic construction to create adverbial expressions, as in Krongo (9), but rather flexibly applies a single class of lexemes in two different propositional functions.

Predicatives fulfill the functions at the two extreme ends of the parts of speech hierarchy. The hierarchy predicts that these lexemes should also be able to express the two intermediate functions (head and modifier of a referential phrase), but this in fact is not the case, as can be seen in Figure 5 below. Note that the two intermediate functions in Kayardild can be expressed by a class of non-verbs, i.e. lexemes that can be used not only as the head and modifier within a referential phrase, but also as a modifier in a predicate phrase. This means that there are in fact two types of lexeme classes that can fulfill the function of modifier in the predicate phrase. The difference between these two classes is that non-verbs, unlike predicatives, take nominal inflection when they are used as manner adverbs (Evans 1995:227-229).

\begin{tabular}{|l|l|l|l|l|}
\hline Language & $\begin{array}{l}\text { head of pred. } \\
\text { phrase }\end{array}$ & $\begin{array}{l}\text { head of ref. } \\
\text { phrase }\end{array}$ & $\begin{array}{l}\text { modifier of } \\
\text { ref. phrase }\end{array}$ & $\begin{array}{l}\text { modifier of pred. } \\
\text { phrase }\end{array}$ \\
\hline Kayardild & predicative & \multicolumn{2}{|c|}{ (non-verbs) } & Predicative \\
\hline
\end{tabular}

Figure 5: Predicatives in the PoS system of Kayardild

The third type of counterexample is attested (among other languages) in Garo (Burlings 1961:27, 33). This language has a rigid parts of speech system, which is like the system in Krongo in that it lacks a class of adjectives and must instead use relative clauses to express the function of modifier in a referential phrase. This is illustrated in (18)-(19):

\footnotetext{
${ }^{4}$ Evans (1995: 86, 303-304) describes the situation as follows: "Verbals primarily denote actions and processes, but may also provide adverbial type information about the manner in which these are carried out (...)." He does mention that there are "a few lexemes [which] only permit the modifier function". However, Evans in fact lists only four such lexical adverbs, and about these remarks that "it is possible that a bigger corpus would see even these used as main verbs". We conclude from this that flexibility between the two functions is systematic in Kayardild.
} 
(18)

Da'r-ay-gen.

big-it-FUT

'It will get big.'

(19)

da'r-gipa mande

big-REL man

'the big man'

The example in (20) makes clear that -gipa is indeed a relativizer rather than a lexical derivational suffix (Burlings 2003:301):

$\begin{array}{llll}{[\text { nok-o }} & \text { pïsa-ko } & \text { nik-gipa }] & \text { metra } \\ \text { house-LOC } & \text { child-ACC } & \text { see-REL } & \text { woman }\end{array}$

'the woman who saw the child at the house'

The parts of speech hierarchy predicts that a language without a separate class of adjectives will not have a class of manner adverbs either. However, Garo does have a large class of derived manner adverbs, which are formed through reduplication of verb stems, as illustrated in (21) and (22). There are also a few basic ones such as tengre 'fast, quickly' (Burlings 2004:101, 267).

jrip-jrang

'soundlessly, silently'

\section{2) ka'sine-ka'sine}

'slowly'

Thus, it is not so much the distribution of the adverb class in Garo that is unpredicted, but rather its existence within the rest of the language's parts of speech system, which is represented in Figure 6:

\begin{tabular}{|l|l|l|l|l|}
\hline language & $\begin{array}{l}\text { head of pred. } \\
\text { phrase }\end{array}$ & $\begin{array}{l}\text { head of ref. } \\
\text { phrase }\end{array}$ & $\begin{array}{l}\text { modifier of } \\
\text { ref. phrase }\end{array}$ & $\begin{array}{l}\text { modifier of pred. } \\
\text { phrase }\end{array}$ \\
\hline Garo & Verb & noun & - & manner adverb \\
\hline
\end{tabular}

Figure 6: Manner adverbs in the parts of speech system of Garo.

In order to account for these three types of counterexamples, a reconsideration of the parts of speech hierarchy is necessary. ${ }^{5}$

\footnotetext{
${ }^{5}$ Note that the three counterexamples discussed in this section do not make reference to the intermediate parts of speech systems discussed in Footnote 2. However, our research (Hengeveld \& Van Lier 2008; Van Lier 2009) shows that the attested cross-linguistic variation in this type of parts of speech system is also more extensive than predicted by the original parts of speech hierarchy. Specifically, the "extra" classes of intermediate parts of speech
} 


\section{A New Two-Dimensional Map of Parts of Speech Systems}

As we noted earlier, the parts of speech hierarchy is based on two parameters, one concerning the opposition between predication and reference, the other between head and modifier. With respect to the former parameter, we expect the function of predication to be privileged in relation to the function of reference since referring expressions can only be created by predicating properties of an entity. Thus, in a noun phrase like a yellow car, the properties "car" and "yellow" are predicated of the entity being referred to (see Bach 1968, Dik 1980: Chapter 4). Regarding the second parameter, heads are obligatory and therefore primary in relation to optional modifiers. This is also shown by the fact that the lexical class of a modifier is dependent on the lexical class of its head. Thus, for each of the two parameters we predict the following hierarchical relations:

\section{Predication $\subset$ Reference}

\section{Head $\subset$ Modifier}

In addition, these two hierarchical relations can in turn be ranked with respect to one another. In view of the fact that there are (appositional) languages that do not use modification at all, while there are no languages that do not display the predication-reference distinction (even though they may not do so at the level of lexical classification, but rather at the level of syntactic constructions), we expect the predication-reference parameter to be primary in relation to the head-modifier parameter, as in (25):

$$
((\text { Predication/Reference }) \subset(\text { Head/Modifier }))
$$

A further consequence of the combined effects of these parameters is that specialization of classes of lexical heads in the predicative domain is expected to precede specialization of classes of lexical heads in the referential domain.

We may now formulate three implicational constraints, which are given in general terms in (26)-(28):

\footnotetext{
systems need not be contiguous, in terms of the hierarchy, to the rightmost large basic class of the particular system. They are also not always derived or small, closed classes. For example, a language may combine a class of contentives with a large, open class of rigid verbs, as is for instance the case in Santali (Neukom 2001). The parts of speech hierarchy would predict that contentives can only be combined with a derived class of non-verbs. In this paper, we will not go further into these cases. For more data and a full discussion we refer to Hengeveld \& Van Lier 2008 and Van Lier 2009, where we show that extra classes are added to parts of speech systems in accordance with the implicational restrictions to be outlined in the next section.
} 


\section{Predication $\subset$ Reference}

a. If a language has a specialized class of lexemes that can be used as the head of a referential phrase, it must also have a specialized class of lexemes that can be used as the head of a predicate phrase, i.e. if a languages has nouns, then it has verbs.

b. If a language has a flexible class of lexemes that can be used as the head of a referential phrase (but not as the head of a predicate phrase since the restriction then becomes irrelevant), it must also have a flexible or specialized class of lexemes that can be used as the head of a predicate phrase, i.e. if a language has nominals or non-verbs, then it has verbs or predicatives.

\section{Head $\subset$ Modifier}

a. If a language has a specialized class of lexemes that can be used as the modifier within a phrase, it must also have a specialized class of lexemes that can be used as the head of that phrase, i.e. if a language has manner adverbs, then it has verbs, and if it has adjectives, then it has nouns.

b. If a language has a flexible class of lexemes that can be used as the modifier within a phrase (but not as the head of that phrase since the restriction then becomes irrelevant), it must also have a flexible or specialized class of lexemes that can be used as the head of that phrase, i.e. if a language has modifiers, or non-verbs, then it has verbs (or a class of flexible heads, but this is excluded by principle (28)); and if a language has modifiers (or non-nouns, ${ }^{6}$ but this is excluded by principle (26a)), then it has nouns (or heads, but these are excluded by principle (28)).

$((\text { Predication/Reference }) \subset(\text { Head/Modifier }))^{7}$

If a language has distinct (specialized or flexible) classes of lexemes for heads and modifiers within any phrase, then it has distinct (specialized or flexible) classes of lexemes for heads of predicate and referential phrases.

The parameters in (23)-(25) and the constraints in (26)-(28) are accounted for in the layered implicational map in Figure 7.

${ }^{6}$ By "non-nouns" we would mean a class of lexemes that can be used in all functions expect the head of a referential phrase.

${ }^{7}$ What we explicitly do not want to suggest is that the Head-Modifier distinction must apply within the predicative domain before it can apply in the referential domain. Thus the combination of (23/26) and (24/27) should not be read as (PredHead $\subset$ PredModifier $) \subset($ RefHead $\subset$ RefModifier). Thanks to Michael Cysouw for pointing this out to us. 


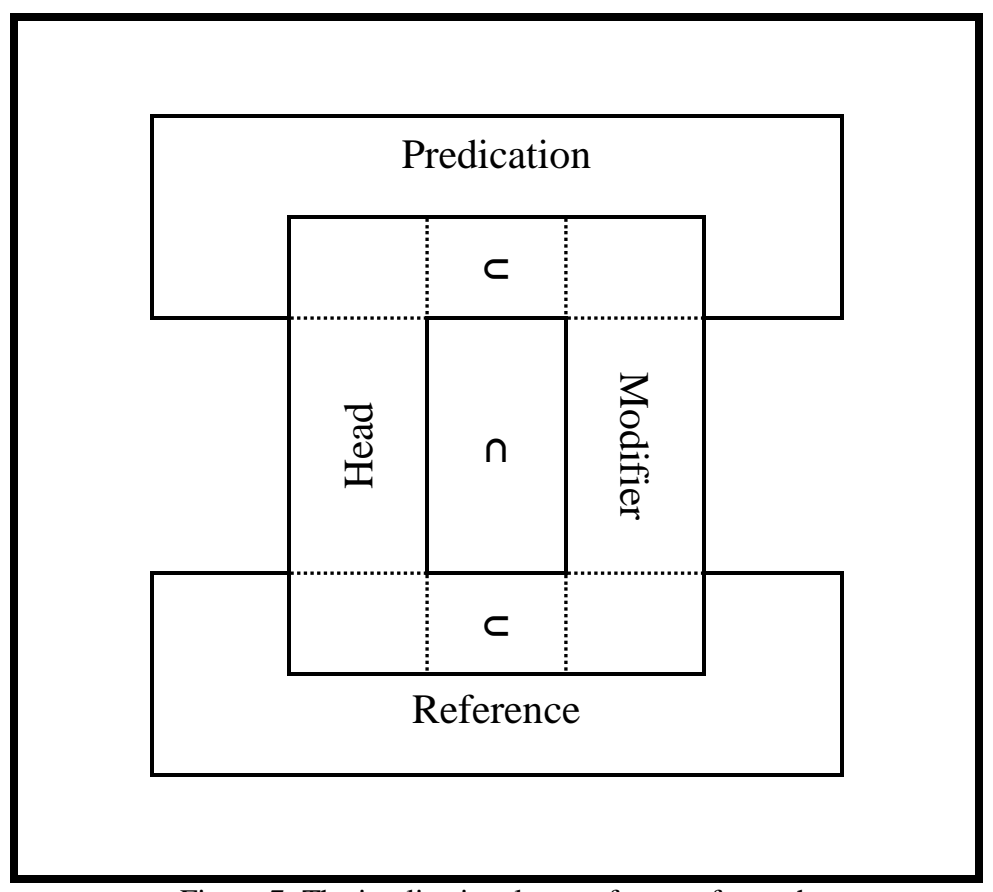

Figure 7: The implicational map of parts of speech

Figure 7 shows that the predication-reference parameter ranks higher than the head-modifier parameter (as indicated by the symbol $\cap$ in the centre), and that the head-modifier parameter applies in the domains of both predication and reference, which does not exclude these domains from sharing a single lexeme class, as in the case of contentives, non-verbs, and modifiers.

\section{Typological Adequacy of the Model: Coverage and Accuracy}

In this section we assess the typological adequacy of the model proposed in the previous section, i.e. the degree to which it is capable of capturing all systems attested so far (coverage), and whether it excludes categories that are not attested (accuracy) (Cysouw 2007).

Starting with coverage, the map in Figure 7 handles all the systems that were consistent with the former parts of speech hierarchy, as shown in the simplified representations in Figures 8-14. The system in Figure 8 is consistent with our model because it involves no lexical distinctions at all. An example of a language that displays this type of PoS system is Kharia (Peterson 2006).

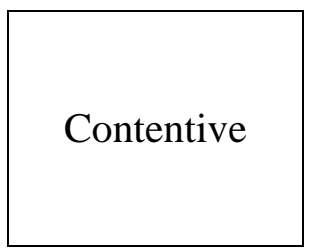

Figure 8

The system in Figure 9 is consistent because it has both a flexible lexeme class that can be used as the head of a referential phrase and a rigid lexeme class for heads in the predicative domain (see (26b)); also because it has both a flexible class of lexemes that can be used as a modifier within the predicate phrase and a rigid class of lexemes that can be used as the head of that 
phrase (see (27b)); and because it has distinct classes for heads and modifiers in the predicate phrase as well as distinct classes for heads of predicative versus referential phrases (see (28)). We have already discussed an example of this PoS system, namely Turkish.

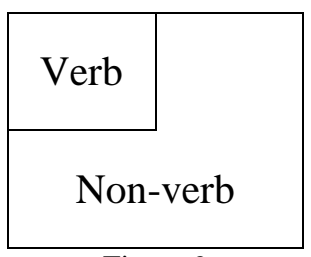

Figure 9

The system in Figure 10 is consistent because it involves a predication-reference distinction for heads but not for modifiers. This is in accordance with constraint (26a): a rigid class of nouns implies a rigid class of verbs. It is also in accordance with constraint (27b): the presence of flexible modifiers implies the presence of rigid heads. Finally, it conforms to constraint (28): distinct classes for heads and modifiers imply distinct classes for the heads of predicative versus referential phrases. This PoS system is relevant for Dutch and German, for example.

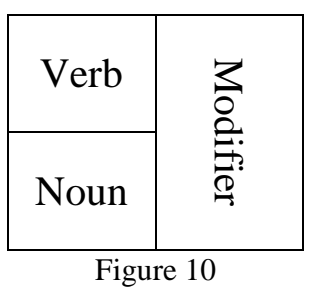

The system in Figure 11 is consistent with the model because it involves head-modifier distinctions in both the predicative and the referential domain. This is in accordance with (26a), (27a), and (28). An example of this type of system is Georgian (Hewitt 1995).

\begin{tabular}{|l|l|}
\hline Verb & MAdv \\
\hline Noun & Adj \\
\hline
\end{tabular}

Figure 11

The system in Figure 12 differs from the one in Figure 11 only in that it lacks a lexeme class for the function of modification in predicate phrases, while the head function in this domain is expressed by verbs. This does not violate any of the constraints above. ${ }^{8}$ A language that has this PoS system is Pipil (Campbell 1985).

\footnotetext{
${ }^{8}$ Note that this would have been a violation of the nested implication (PredHead $\subset$ PredModifier) $\subset($ RefHead $\subset$ RefModifier), cf. note 7.
} 


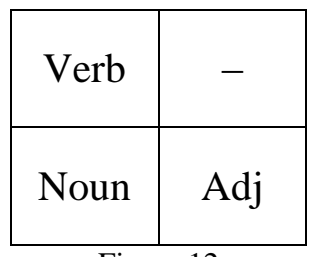

Figure 12

The system in Figure 13 again has a predication-reference distinction in the head domain but does not have lexical classes for either of the two modifier functions. This system conforms to (26a) since it has rigid classes of heads in both the reference and the predication domain, while constraints (27) and (28) are not applicable. We have shown above that this system is attested in Krongo.

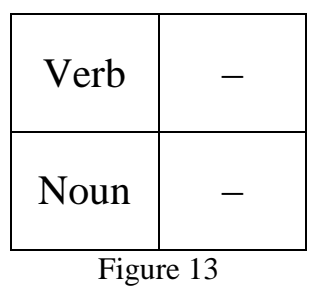

The system in Figure 14, finally, has only one lexical class, namely one that fulfills the function of head of a predicate phrase. This does not violate any of the constraints. This system has not been attested in its pure form. However, there are certain languages that clearly place a larger burden on verbs than on nouns, in the sense of resorting to predicative constructions where many languages would use noun phrases. Tuscarora (Mithun 2000) and Hupa (Golla 1985) are examples of such languages.

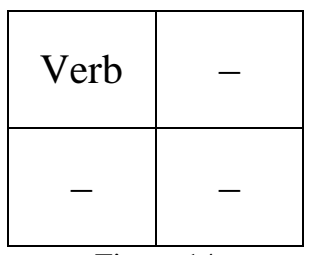

Figure 14

In addition to the previous systems, the implicational map in Figure 7 also covers the counterexamples to the former parts of speech hierarchy discussed in Section 3. These systems are shown in Figures 15-17.

The system in Figure 15 is in accordance with (26b) since it has a flexible class for referential heads and a rigid class of predicative heads. It is also in accordance with (27a) in the predication domain, where it has rigid modifiers and rigid heads. Finally, it conforms to (28), since it has distinct classes for heads and modifiers in the predicate phrase, as well as distinct classes for heads in predicative versus referential phrases. This system is attested, for instance, in Hungarian, as we have seen. 


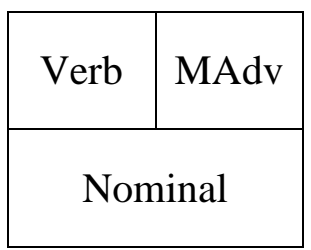

Figure 15

The system in Figure 16 involves a lexical distinction between predication and reference but not between heads and modifiers. This system is in accordance with (26b). Constraints (27) and (28) are not applicable. As we have shown above, so far this type of system has not been attested in its exact form; Kayardild does have predicatives but in combination with non-verbs rather than nominals.

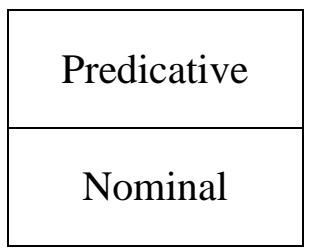

Figure 16

Finally, the system in Figure 17 has rigid lexeme classes for heads and modifiers in the predication domain, while in the reference domain it has a rigid lexeme class for heads. Thus, it is in accordance with (26a), (27a), and (28). This system has been illustrated above with Garo.

\begin{tabular}{|c|c|}
\hline Verb & MAdv \\
\hline Noun & - \\
\hline
\end{tabular}

Figure 17

It is to be noted that our model predicts seven further possible systems, namely those presented in Figures 18-24. The system in Figure 18 is in accordance with our constraint (26b), while (27) and (28) are not applicable. We have attested this system only in combination with a small, closed class of manner adverbs (cf. Figure 15), for instance in Nhanda (Blevins 2001).

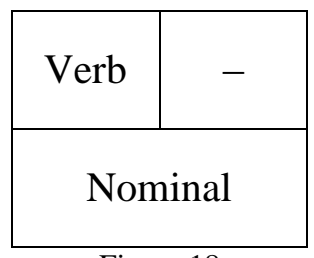

Figure 18

The system in Figure (19) conforms to constraint (26b) since it has a flexible class of lexemes that can be used predicatively while not having a class of lexemes that can be used referentially. Constraints (27) and (28) do not apply. We have not attested this system in any language. 


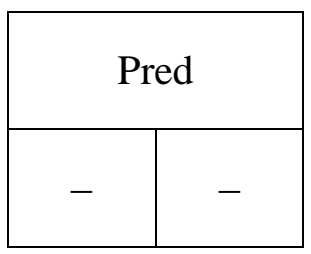

Figure 19

The system in Figure 20 involves a single flexible class of heads, which can be used in both predicative and referential phrases. It does not violate any of our constraints. This system has not been attested as such. However, it does seem to occur as an intermediate type in combination with the system in Figure 13 above. Languages like Nivkh (Matissen \& Drossard 1998) and West Greenlandic (Fortescue 1984, Sadock 2003) apparently have rigid classes of nouns and verbs, as well as a class of lexemes that can be used as both.

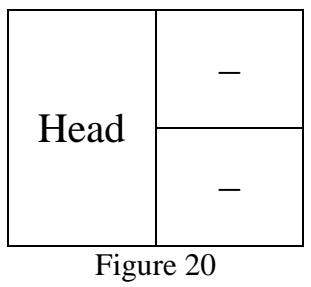

The system in Figure 21 also involves a single flexible class but one that can be used in all functions except modifier in a predicate phrase. This system does not violate any of the constraints. ${ }^{9}$ Tagalog has this type of system. In this language, all content words can be used in all functions except that of modifier of a predicate phrase. To express the latter function, a predicative construction is used, as can be seen in example (29) below (Himmelmann 2007).

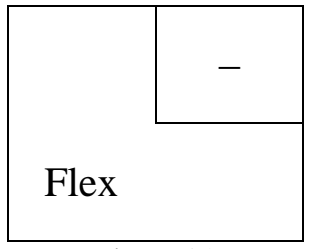

Figure 21

$$
\begin{array}{llll}
\text { biglaan } & \text { ang } & \text { kanyá-ng } & \text { alís. } \\
\text { sudden } & \text { SPEC } & \text { 3.SG.DAT-LK } & \text { departure }
\end{array}
$$

'He left suddenly.' (lit. 'His departure was sudden.')

The system in Figure 22 is similar to the one in Figure 21, except that the flexible class can now be used in all functions except modifier in a referential phrase. So far we have not attested this type of system.

\footnotetext{
${ }^{9}$ Note that the lack of a lexeme class for the function of modifier in the predication domain does not mean that there is a head-modifier distinction in this domain.
} 


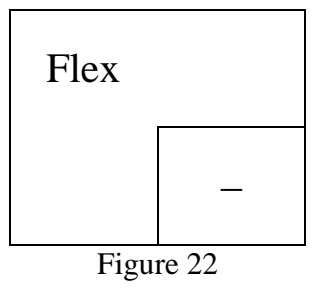

The system in Figure 23 has a flexible class of lexemes that can be used as the head of a referential phrase and a modifier in a predicate phrase, but not as a modifier in a referential phrase. This system has not been attested either.

\begin{tabular}{|c|c|}
\hline Verb & Flex \\
\hline Flex & - \\
\hline
\end{tabular}

Figure 23

Finally, the system in Figure 24 involves two flexible lexeme classes: one class (Flex1) that can be used as the head of a predicate phrase and as a modifier in a referential phrase, and another class (Flex2) that can be used as the head of a referential phrase and as a modifier in a predicate phrase. We have not attested this system in any language. In fact, this does not seem surprising, since both flexible classes in this system neutralize distinctions between opposite values of both the predication-reference and the head-modifier parameter. Intuitively, it would seem more probable to expect flexibility in cases where at least one parameter's value is shared. However, on the basis of our restrictions, as formulated in (26), (27), (28), we are not able to exclude the system in Figure 24.

\begin{tabular}{|l|l|}
\hline Flex1 & Flex2 \\
\hline Flex2 & Flex 1 \\
\hline
\end{tabular}

Figure 24

To summarize, our model predicts 17 possible PoS systems of which 7 were also predicted by the former parts of speech hierarchy. Of these 17 systems, we have attested 9 in their "pure" form (the systems in Figures 8, 9, 10, 11, 12, 13, 15, 17, and 21) and 4 in some kind of intermediate form, i.e. in combination with other types of systems (the ones in Figures 14, 16, 18, and 20). Four systems (the ones in Figures 19, 22, 23, and 24) are predicted to be possible, but have not (yet) been attested by us.

Regarding accuracy, the model excludes 34 out of a total of 51 logically possible systems. Below, we list these systems one by one (Figures 25-58) and explicate which constraint(s) each of them violates. None of the excluded systems have been attested by us.

The system in Figure 25 is excluded since it has only one rigid class of heads, not in the predication domain but in the reference domain. As such it violates constraint (26a). 


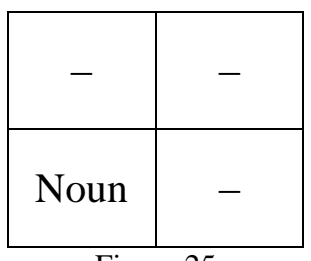

Figure 25

The system in Figure 26 has a rigid class of modifiers in the referential domain without the corresponding rigid class of heads. As such it violates constraint (27a).

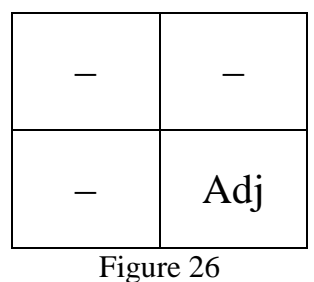

The system in Figure 27 also violates constraint (27a) since it has a rigid class of modifiers without the corresponding rigid class of heads, this time in the predication rather than in the reference domain.

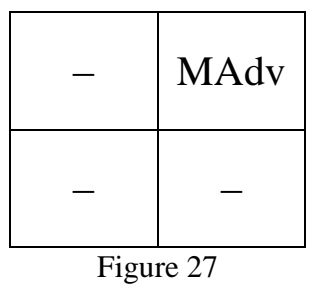

The system in Figure 28 has distinct classes of heads and modifiers in the predication domain, whereas it does not have distinct classes for heads of predicative versus referential phrases. Thus, constraint (28) is violated.

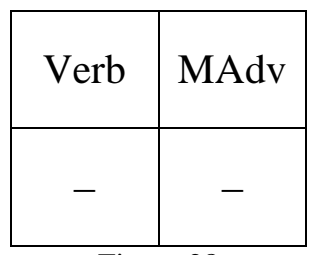

Figure 28

The system in Figure 29 violates constraint (27a) since is has a rigid class of modifiers in the reference domain without the corresponding rigid class of heads. 


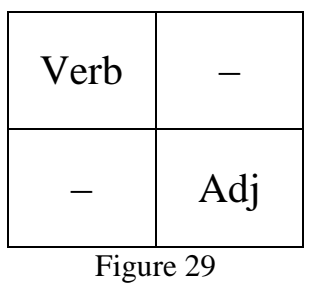

The system in Figure 30 violates two constrains: there is a single rigid class of heads but not in the predication domain. Thus, constraint (26a) is violated. In addition, there is a head-modifier distinction in the referential domain, but there are no distinct classes of lexemes for heads of predicative versus referential phrases, so that constraint (28) is violated as well.

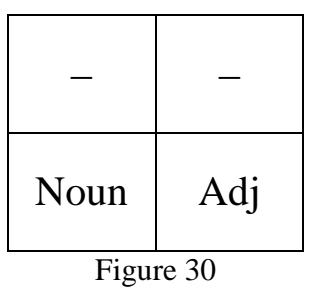

The system in Figure 31 also violates two constraints: it has a single rigid class of heads, but not in the predication domain, so that (26a) is violated. Furthermore, (27a) is violated in the predication domain where there is a rigid modifier class without the corresponding rigid head class.

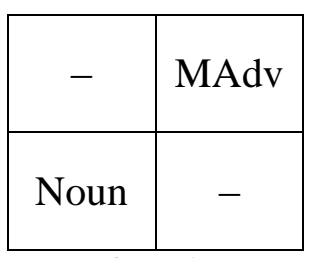

Figure 31

The system in Figure 32 has two rigid classes of modifiers without the corresponding rigid classes of heads, so that (27a) is violated in both the predication and the reference domain.

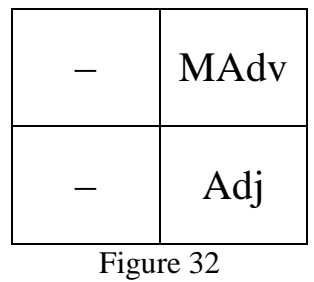

The system in Figure 33 violates three constraints: (26a) since there are rigid heads in the referential but not in the predicative domain: (27a) since in the predication domain there is a rigid modifier class but no rigid head class; and (28) because there is a head-modifier distinction in the referential domain but no distinct classes for heads of predicative versus referential phrases. 


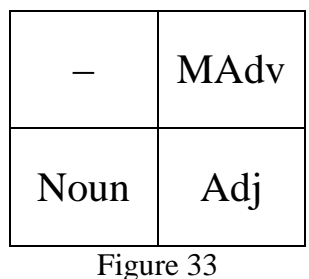

The system in Figure 34 violates constraint (27a) since it has a specialized class of lexemes that can be used as the modifier in a referential phrase but has no lexeme class to express the head of a referential phrase. In addition, this system violates constraint (28) since it has distinct classes for heads and modifiers in predicate phrases but has no distinct classes for heads of referential phrases as opposed to predicate phrases.

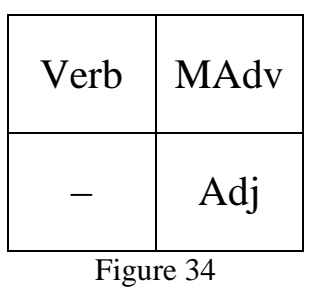

The system in Figure 35 violates constraint (28): there is lexical distinction between heads and modifiers but no distinct classes for heads of predicative versus referential phrases.

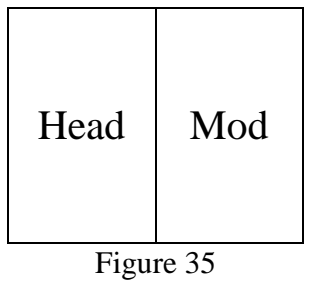

The system in Figure 36 is excluded since it has two rigid classes of modifiers without the corresponding rigid classes of heads. As such it violates constraint (27a) in both the predication and the reference domain.

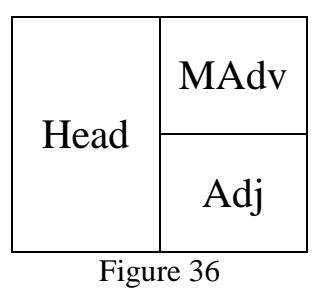

The system in Figure 37 is excluded because it violates constraint (27a): it has a specialized class of lexemes that can be used as the modifier in a predicate phrase, but it does not have a specialized class for heads of predicate phrases. 


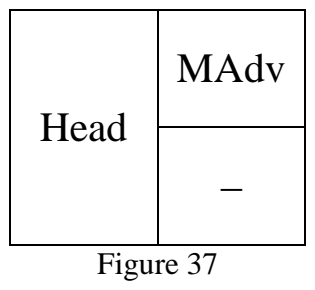

The system in Figure 38 also violates constraint (27a), but in the referential domain, where it has a specialized class of modifiers but not a specialized class of heads.

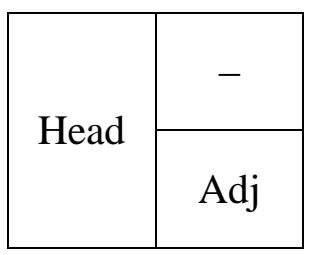

Figure 38

The system in Figure 39 is excluded because it has a class of lexemes that can be used as the head of a referential phrase but has no class of lexemes that can be used as the head of a predicate phrase (verbs or predicatives). Thus, it violates constraint (26b).

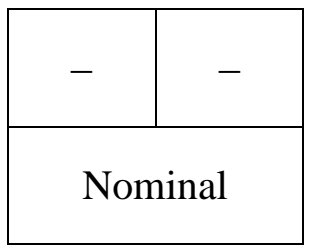

Figure 39

The system in Figure 40 violates two constraints: it has a flexible class of lexemes that can be used as the head of a referential phrase but no class of lexemes that can be used as the head of a predicate phrase. Thus, it violates (26b). In addition, it has a rigid class of modifiers in the predication domain but does not have the corresponding heads, so that it also violates (27a).

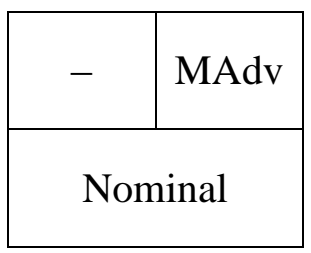

Figure 40

The system in Figure 41 violates constraint (27b): it has a flexible class of modifiers but no heads, i.e. nouns and verbs. 


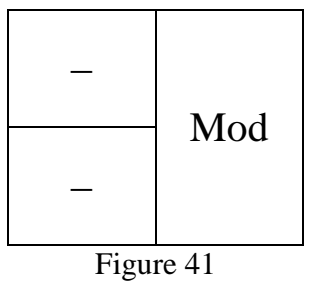

The system in Figure 42 is excluded because it violates constraint (28): there is lexical distinction between heads and modifiers in the predication domain, but there are no distinct classes for heads of predicative versus referential phrases.

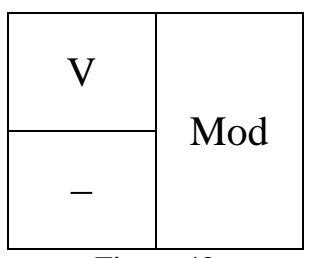

Figure 42

The system in Figure 43 also violates constraint (28). In addition, it violates constraint (26a): it has a rigid class of heads for referential but not for predicate phrases.

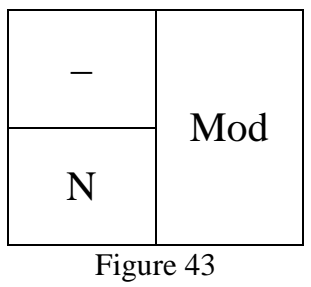

The system in Figure 44 has a flexible class of lexemes that can be used as the head of a referential phrase but does not have a class of lexemes that can be used as the head of a predicate phrase (verbs). Thus, it violates constraint (26b). Furthermore, it has a flexible class of lexemes that can be used as a modifier in the predicated phrase without a class of rigid heads for this phrase. Thus, it also violates constraint (27b).

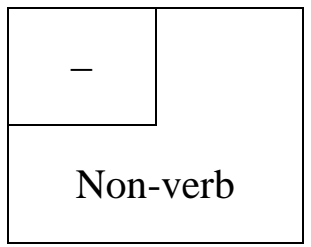

Figure 44

The system in Figure 45 is excluded on the basis of constraint (27b): it has a flexible class of lexemes that can be used as the modifier (but not the head) in a referential phrase, but it does not have the corresponding class of heads. 


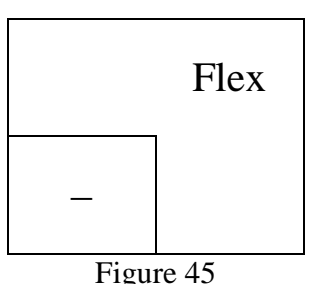

The system in Figure 46 is excluded because it has a rigid head class in the referential but not in the predication domain. As such, it violates constraint (26a).

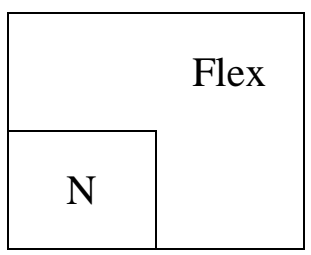

Figure 46

The system in Figure 47 involves a rigid modifier class in the referential domain without the corresponding rigid head class and thus violates (27a). In addition, it involves distinct classes for heads and modifier in the referential domain without distinct classes of heads of predicative versus referential phrases. Thus, it also violates (28).

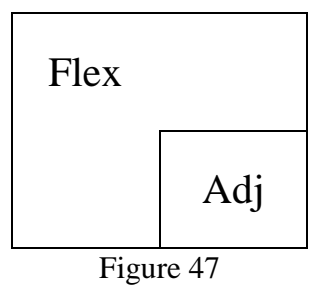

The system in Figure 48 is excluded for the same reasons as the system in Figure 47, except that constraint (27a) is now violated in the predication domain.

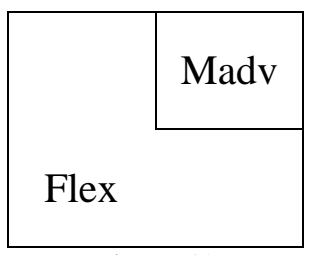

Figure 48

The system in Figure 49 violates constraint (26a): it has a rigid class of heads in the referential but not the predication domain.

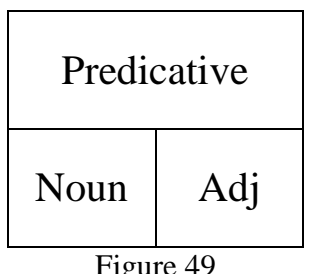

Figure 49 
For the same reason, the system in Figure 50 is excluded:

\begin{tabular}{|c|c|}
\hline \multicolumn{2}{|c|}{ Predicative } \\
\hline Noun & - \\
\hline
\end{tabular}

Figure 50

The system in Figure 51 violates constraint (27a): it has a class of rigid modifiers in the reference domain but not the corresponding rigid class of heads.

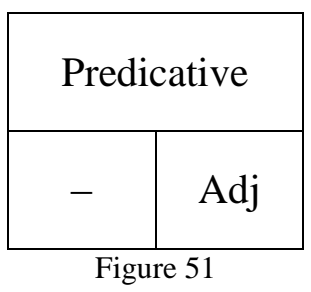

The system in Figure 52 involves a flexible class of lexemes that can be used as the heads of a referential phrase and as a modifier in a predicate phrase. It is excluded because it violates constraint (27a) in the reference domain, where it has a rigid modifier class without a rigid head class.

\begin{tabular}{|l|l|}
\hline Verb & Flex \\
\hline Flex & Adj \\
\hline
\end{tabular}

The system in Figure 53 is excluded because it violates four constraints. It violates constraint (26b) because it has a flexible lexeme class that can be used as the head of a referential phrase but has no lexeme class for heads of predicate phrases. In addition, this system violates constraint (27a) in the reference domain since it has a specialized class of lexemes for modification in the referential phrase but no specialized class for heads of referential phrases. It also violates constraint (27b) because it has a flexible class of lexemes that can be used as the modifier (but not the head) of a predicate but has no lexical class for heads in predicate phrases. Finally, this system violates constraint (28): it has distinct classes for heads and modifiers in referential phrases but no distinct class for heads of predicate phrases.

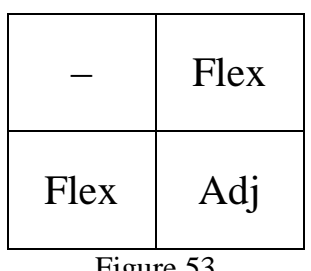

Figure 53 
The system in Figure 54 is excluded because it violates constraint (26b): it has a flexible lexeme class that can be used as the head of a referential phrase but no lexeme class for heads of predicate phrases. In addition, this system violates constraint (27b) in the predication domain, where it has a flexible class of lexemes that can be used for modification but has no class for heads.

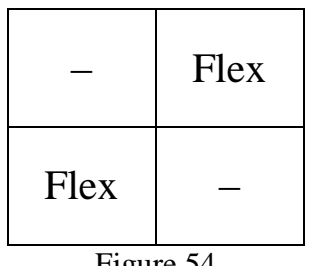

Figure 54

The system in Figure 55 involves a flexible lexeme class that can be used as the head of a predicate phrase and as a modifier in a referential phrase. It is excluded because it violates constraint (26a): it has a rigid class of heads in the referential but not in the predication domain. In addition, it violates constraint (27a) in the predication domain, where it has a rigid modifier class but no rigid head class.

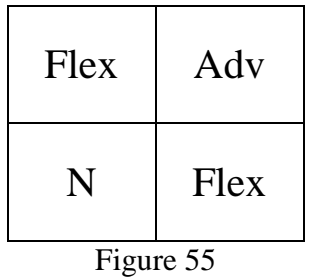

It should be stressed that the system in Figure 55 does not represent the situation found in languages with predicative adjectives (or "verby" adjectives (Stassen 1997)). Although in such languages it may be the case that all adjectives can be used as verbs, the reverse is not true: when verbs are used as referential modifiers, they take the form of relative clauses. This occurs for instance in Berbice Dutch Creole (Kouwenberg 1994). This means that there is no bi-directional flexibility (cf. Evans \& Osada 2005).

The system in Figure 56 is excluded because it violates constraint (26a): it has a rigid class of heads in the referential but not in the predication domain.

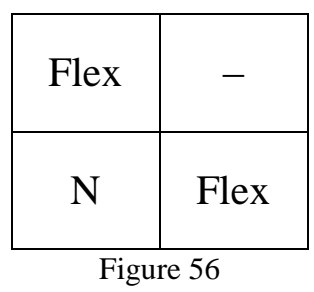

The system in Figure 57 is excluded because it violates constraint (27a) in the predication domain, where it has a specialized class for modifiers but a flexible class for heads. In addition, this system violates constraint (27b) in the reference domain, where it has a flexible class for modifiers but no class for heads. Finally, this system violates constraint (28): it has distinct 
classes for heads and modifiers in the predicate phrase but has no distinct classes for heads of referential phrases, as opposed to predicate phrases.

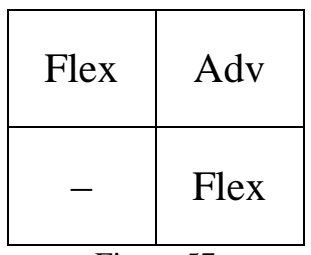

Figure 57

The system in Figure 58 violates constraint (27b) since it has a flexible lexeme class that can be used as a modifier in a referential phrase but has no lexeme class that can be used as the head of a referential phrase.

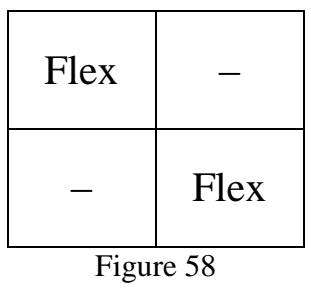

In summary, this section shows that the new implicational map of parts of speech has increased typological adequacy compared to the original parts of speech hierarchy. In particular, this new approach predicts 17 possible systems out of 51 logical possibilities. Out of the 17 predicted systems, 9 are attested in their pure form and 4 in intermediate type systems. Another 4 predicted systems have not (yet) been attested. The model excludes 34 systems out of the 51 logically possible ones. We have attested none of the excluded systems in actual languages.

\section{Conclusion: From Semantic to Implicational Maps}

The model proposed in this paper can be related in several ways to the general methodology of semantic maps. First, our model shows that analytical primitives of "semantic" maps need not be exclusively semantic in nature but may also include other domains of grammar, which is why we use the term "implicational" map in the title of this paper. In the parts of speech map, the predication-reference parameter and the head-modifier parameter each pertain to different functional dimensions, neither of which is connected to the denotational semantics expressed by the linguistic units involved but rather connected to ways in which lexical items are used to create predicating and referring expressions.

Second, the proposed new analysis of parts of speech systems uses what has become known as the "semantic map" methodology to analyse an important morpho-syntactic property of languages. As Haspelmath $(1997,2001)$ points out, implicational maps embody a series of implicational universals. In this paper we have tried to take this approach one step further by introducing hierarchical ranking of different types of implicational relations. In other words, we have attempted to create an implicational map that is an instantiation of a hierarchy of hierarchies. It is evident that the potential recursivity of this procedure takes us from twodimensional implicational maps to multidimensional implicational networks, which require other forms of visualization and a more sophisticated analytical methodology. 
In taking this approach, a serious problem of the semantic map methodology is avoided. As Haspelmath (2003) and Cysouw (2007) note, traditional semantic maps are not specified for frequency of attestation of a specific language structure since they plot contiguity constraints and diachronic pathways that are not by themselves implicational in nature. This does not hold for the map proposed in the present paper: by combining implicational hierarchies in a single model and ranking them with respect to each other, it predicts which parts of speech are less marked along two dimensions, and therefore more frequently attested (e.g. verbs), and which parts of speech are more marked along two dimensions, and therefore less frequently attested (e.g. adjectives).

\section{Abbreviations}

Abbreviations used in this paper and not standardized in the Leipzig Glossing Rules:

ACT active voice, CONN connector, ELAT elative case, ESS essive case, LK linker, SPEC specifier

\section{References}

Bach, Emmon. 1968. Nouns and noun phrases. Universals in linguistic theory, ed. by Emmon Bach and Robert T. Harms, 91-122. New York: Holt, Rinehart and Winston.

Blevins, Juliette. 2001. Nhanda: An Aboriginal Language of Western Australia. Honolulu: University of Hawai'i Press. (Oceanic Linguistics Special Publication 30).

Burling, Robbins .1961. A Garo grammar. Poona: Deccan College. (Deccan College Monograph Series 25).

-----. 2004. The language of the Modhupur Mandi (Garo), vol. 1: Grammar. New Delhi/Morganville: Bibliophile South Asia/Promilla \& Co.

Campbell, Lyle. 1985. The Pipil language of El Salvador. Berlin: Mouton de Gruyter. (Mouton Grammar Library 1).

Croft, William. 2000. Parts of speech as language universals and as language-particular categories. Approaches to the typology of word classes, ed. by Petra M. Vogel and Bernard Comrie, 65-102. Berlin: Mouton de Gruyter.

-----. 2001. Radical Construction Grammar. Oxford: Oxford University Press.

Cysouw, Michael. 2007. Building semantic maps: The case of person marking. New challenges in typology: Broadening the horizons and redefining the foundations, ed. by Matti Miestamo and Bernhard Wälchli, 225-248. Berlin: Mouton de Gruyter.

Dik, Simon C. 1980. Studies in Functional Grammar. London: Academic Press.

Evans, Nicholas D. 1995. A grammar of Kayardild. Berlin: Mouton de Gruyter. (Mouton Grammar Library 15).

Evans, Nicholas and Toshiki Osada. 2005. Mundari: The myth of a language without word classes. Linguistic Typology 9/3.351-390.

Fortescue, Michael D. 1984. West Greenlandic. London: Croom Helm. (Croom Helm Descriptive Grammars).

Göksel, Aslı and Celia Kerslake. 2005. Turkish: A comprehensive grammar. New York: Routledge.

Golla, Victor. 1985. A short practical grammar of Hupa. Hoopa Valley: Hupa Language Program.

Haspelmath, Martin. 1997. Indefinite pronouns. Oxford: Oxford University Press. 
-----. 2003. The geometry of grammatical meaning: Semantic maps and cross-linguistic comparison. The new psychology of language, ed. by Michael Tomasello, vol. 2, 211-242. Mahwah, NJ: Erlbaum.

Hengeveld, Kees. 1992. Non-verbal predication: Theory, typology, diachrony. Berlin: Mouton de Gruyter. (Functional Grammar Series 15).

Hengeveld, Kees, Jan Rijkhoff and Anna Siewierska. 2004. Parts-of-speech systems and word order. Journal of Linguistics 40.527-570.

Hengeveld, Kees and Eva van Lier. 2008. Parts of speech and dependent clauses in Functional Discourse Grammar. Parts of speech: Descriptive tools, theoretical constructs, ed. by Umberto Ansaldo, Jan Don and Roland Pfau. Special issue of Studies in Language 32/3.753785.

Hewitt, Brian G. 1995. Georgian: A structural reference grammar. Amsterdam: Benjamins. (London Oriental and African language library 2).

Himmelmann, Nikolaus P. 2007. Lexical categories and voice in Tagalog. Voice and grammatical functions in Austronesian languages, ed. by Peter Austin and Simon Musgrave. Stanford: CSLI.

Kenesei, István, Robert M. Vafo and Anna Fenyvesi. 1998. Hungarian. London: Routledge.

Kouwenberg, Silvia. 1994. A grammar of Berbice Dutch Creole. Berlin: Mouton de Gruyter. (Mouton Grammar Library 12).

Lier, Eva van. 2006. Parts-of-speech and dependent clauses: A typological study. Folia Linguistica 40/3-4.239-304.

-----. 2009. Parts-of-speech and dependent clauses. Utrecht: LOT Publications. (LOT dissertation series 221)

Matissen, Johanna and Werner Drossard. 1998. Lexical and syntactic categories in Nivkh (Gilyak). Düsseldorf: Heinrich-Heine-Universität. (Arbeiten des Sonderforschungsbereichs 282 "Theorie des Lexikons", No. 85).

Mithun, Marianne. 2000: Noun and verb in Iroquoian languages: Multicategorization from multiple criteria. Approaches to the typology of word classes, ed. by Petra M. Vogel and Bernard Comrie. 397-420. Berlin: Mouton de Gruyter.

Moravcsik, Edith. 2000. On the nouniness of Hungarian adjectives. Naturally! Linguistic studies in honour of Wolfgang Ulrich Dressler, presented on the occasion of his 60th birthday, ed. by Chris Schaner-Wolles, John Rennison and Friedrich Neubarth, 337-346. Turin: Rosenberg and Sellier.

Neukom, Lukas. 2001. Santali. München: Lincom.

Noonan, Michael P. 1992. A grammar of Lango. Berlin: Mouton de Gruyter. (Mouton Grammar Library 7).

Paul, Waltraud. 2005. Adjectival modification in Mandarin Chinese and related issues. Linguistics 43/4.757-793.

Peterson, John. 2006. Kharia: A South Munda language, vol.1: Grammatical analysis. Habilitationsschrift, Universität Osnabrück.

Sadock, Jerrold M. 2003. A grammar of Kalaallisut (West Greenlandic Inuttut). München: LINCOM Europa. (Languages of the world/Materials 162).

Stassen, Leon. 1997. Intransitive predication. Oxford: Oxford University Press. 
Authors' contact information:

Kees Hengeveld

Department of Theoretical Linguistics

University of Amsterdam

Spuistraat 210

1012 VT Amsterdam

The Netherlands

p.c.hengeveld@uva.nl

Eva van Lier

Department of Linguistics and English Language

Lancaster University

LA1 4YT Lancaster

United Kingdom

e.vanlier@lancaster.ac.uk 